\title{
Rapid analysis of leukocyte-endothelial adhesion
}

\author{
Ara A. Vaporciyan, Michael L. Jones and Peter A. Ward \\ Department of Pathology, University of Michigan Medical School, Ann Arbor, MI 48109-0602, USA
}

(Received 5 August 1992, revised received 21 September 1992, accepted 23 September 1992)

\begin{abstract}
Neutrophil adherence to endothelial monolayers in multi-well plates can be rapidly quantitated, using a fluorescent plate reader. The number of adherent neutrophils which have been labeled with biscarboxyethyl carboxyfluorescein (BCECF) was calculated by comparing fluorescence of endothelial monolayers to a reference standard curve determined by fluorescence intensity of suspensions of labeled neutrophils. The limit of sensitivity approached 1000 cells, which is similar to that achieved by the most sensitive of alternate techniques. The assay, after isolation of the neutrophils, can be completed in $1.5 \mathrm{~h}$. The ability to utilize microwell plates permits the use of large numbers of samples. This method has the advantage of being relatively simple and rapid while maintaining a sensitivity comparable to alternate approaches which employ radioactive labeling or counting of adherent or non-adherent cells.
\end{abstract}

Key words: Adhesion; Neutrophil; Endothelium; Fluorescent

\section{Introduction}

A critical role in the initiation of inflammation is the upregulation and activation of adhesionpromoting molecules on the vascular endothelium and on leukocytes. This cell-cell interaction has been the subject of intense investigation both in vitro and in vivo. Numerous animal models of pulmonary, dermal, cardiac and renal injury have demonstrated the importance of these molecules

Correspondence to: P.A. Ward, Department of Pathology, University of Michigan Medical School, 1301 Catherine Street, Box 0602, Ann Arbor, MI 48109-0602, USA. Tel.: (313) 7636384; Fax: (313) 763-4782.

Abbreviations: BCECF-AM, 2',7'-bis-(2-carboxyethyl)5(and-6)-carboxyfluorescein, acetoxymethyl; HUVEC, human umbilical vein endothelial cells; ACD, anticoagulant citrate dextrose; HBSS/BSA, Hanks' buffered salt solution with $0.02 \%$ bovine serum albumin; TNF $\alpha$, tumor necrosis factor alpha; PMA, phorbol 12-myristate acetate. in the development of tissue injury (Cosimi et al., 1990; Lindbom et al., 1990; Flavin et al., 1991; Mulligan et al., 1991). Work in these models has also shown that the involvement of adhesion molecules differs between models, especially with regard to the cytokines and adhesion molecules involved, as well as the time course of upregulation of adhesion molecules. In order to better delineate the various pathways involved numerous in vitro assays must be performed.

The in vitro assays of cell-cell adhesion are broadly divided into static or dynamic models. The method described in this report involves a static system in which the neutrophils are allowed to settle and adhere without any flow-related dynamics. Most in vitro assays of static adhesion have been utilized due to the relatively simple and rapid method of screening adhesive interactions. The ideal method would be one that is highly sensitive, rapidly and easily performed, pose minimal hazards to the investigator and 
allow the screening of large numbers of samples. The simplest system, though somewhat tedious, involves counting bound cells either visually, under a microscope (Beesley et al., 1978), or using a particle counter to assess non-adherent cells (McFaul and Bowman, 1990). This method is sensitive but very labor-intensive. The more commonly used methods rely upon radiolabeling of leukocytes with either $\left[{ }^{3} \mathrm{H}\right]$ thymidine (Roszkowski et al., 1989), $\left[{ }^{3} \mathrm{H}\right]$ adenine (Curwen et al., 1982) or ${ }^{51} \mathrm{Cr}$ (Haskard et al., 1989) and measuring the residual radioactivity after washing away non-adherent cells. Although this method is sensitive, rapid, and easier than counting, it requires the use of radiochemicals. Alternatives have been suggested such as staining with a dye (e.g. rose Bengal) (Gamble and Vadas, 1988) after removing non-adherent cells and measuring optical density. This method is simple and, if a plate reader is utilized, very expeditious. However, it suffers from a relatively low sensitivity when compared to other methods. In the case of lymphocytes, their staining with fluorescent compounds and measuring residual fluorescence has also been used (Pearce-Pratt and Phillips, 1992). This method maintains the sensitivity found in systems employing radioactive labels. The speed of this fluorescent method is limited by the inability of conventional fluorimeters to read multiple samples simultaneously. The advent of the fluorescent plate reader, however, allows the combination of the sensitivity (obtained with fluorochromes) and the speed of spectrophotometric plate readers.

In this paper we describe the use of the fluorescent reporter bis-(carboxyethyl)-carboxyfluorescein, acetoxymethyl (BCECF-AM) to measure in a rapid and sensitive manner adhesive interactions between human neutrophils and endothelial monolayers.

\section{Materials and methods}

\section{Endothelial cell culture}

Human umbilical vein endothelial cells (HUVEC) were isolated by collagenase treatment of umbilical cords and plated onto gelatin-coated plastic flasks (Falcon) (Jaffe, 1984). Dulbecco's modified Eagle's medium with Ham's F-12 and $20 \%$ heat inactivated fetal calf serum was supplemented with $2 \mathrm{mM}$ L-glutamine, $50 \mathrm{IU} / \mathrm{ml}$ penicillin, $50 \mu \mathrm{g} / \mathrm{ml}$ streptomycin, $25 \mathrm{mg} / \mathrm{ml}$ endothelial cell growth supplement (Collaborative Research) and 15 units $/ \mathrm{ml}$ bovine heparin in order to maintain the cells. HUVEC were used between the first and third passage and were characterized by a cobblestone appearance with specific staining for von Willibrand's factor.

\section{Preparation of neutrophils}

Whole blood from healthy human volunteers was collected and anticoagulated with citrate dextrose solution (ACD). Neutrophils were isolated by gradient centrifugation over Ficol-hypaque (Pharmacia). Dextran sedimentation was then used to separate neutrophils from erythrocytes (Barker et al., 1991). Remaining erythrocytes were removed using hypotonic lysis and the remaining cells washed twice with Hanks' buffered salt solution (absent calcium or magnesium), supplemented with $0.02 \%$ bovine serum albumin (HBSS/BSA). Cell suspensions were adjusted to $5 \times 10^{6}$ cells $/ \mathrm{ml}$. Viability was greater than $95 \%$ (by trypan blue exclusion) and $>95 \%$ of the cells were neutrophils.

\section{Fluorescent labeling of neutrophils}

$50 \mu \mathrm{g}$ aliquots of $2^{\prime}, 7^{\prime}$-bis-(2-carboxyethyl)5(and-6)-carboxyfluorescein, acetoxymethyl (Molecular Probes) (BCECF-AM) (MW 821 $\mathrm{g} /$ mole) were freshly dissolved in $50 \mu \mathrm{l}$ dimethyl sulfoxide. This was then added to the neutrophil suspension to give the desired final concentration of BCECF-AM. The mixture was then incubated for $30 \mathrm{~min}$ at $37^{\circ} \mathrm{C}$, following which the cells were washed twice with $4^{\circ} \mathrm{C}$ HBSS/BSA, then resuspended in HUVEC medium at $4^{\circ} \mathrm{C}$. Cells were counted, the concentration adjusted and the suspension was maintained at $4^{\circ} \mathrm{C}$. Viability was greater than $95 \%$ after staining.

\section{Quantification of cell number by fluorescence}

Serial two-fold dilutions of stained neutrophils from $1 \times 10^{6}$ to $1.95 \times 10^{3}$ cells $/ \mathrm{ml}$ was performed. Cells were then placed into 96-well flatbottom fibronectin-coated plates in $100 \mu 1$ aliquots. Fluorescence was determined using the Cytofluor 2300 fluorescent plate reader (Milli- 
pore). The excitation filter was a $20 \mathrm{~nm}$ bandwidth filter centered at $485 \mathrm{~nm}$, and the emission filter was a $25 \mathrm{~nm}$ bandwidth filter centered at $530 \mathrm{~nm}$, which corresponds well with BCECF's excitation maximum of $500 \mathrm{~nm}$ and emission maximum of $530 \mathrm{~nm}$.

\section{Assay of neutrophil adherence to HUVEC mono- layers}

HUVEC were plated at $5 \times 10^{4}$ cells $/$ well in 96-well flat-bottom fibronectin-coated plates and incubated at $37^{\circ} \mathrm{C}$ with $5 \% \mathrm{CO}_{2}$ for $18-24 \mathrm{~h}$. The monolayers were then washed twice with fresh HUVEC media. Recombinant TNF $\alpha$ was added to appropriate wells and the plates incubated at $37^{\circ} \mathrm{C}$ with $5 \% \mathrm{CO}_{2}$ for indicated times. After a gentle wash, $1 \times 10^{5}$ fluorescent labeled neutrophils were then added to each well. A standard curve of cell number to fluorescence was prepared on each plate by performing two-fold serial dilutions of labeled neutrophils, from $1 \times$ $10^{5}$ to $6.25 \times 10^{3}$ cells $/$ well. The plate was incubated for $30 \mathrm{~min}$ at $37^{\circ} \mathrm{C}$ with $5 \% \mathrm{CO}_{2}$. The non-adherent neutrophils were removed with gentle washing. Washing with fresh HUVEC medium involved three techniques: aspiration for three cycles, gentle plate agitation followed by aspiration for three cycles or gentle pipetting of media back and forth four times with a 12-channel multi-pipettor, for two cycles, each involving a new aliquot of buffer. The final method yielded the best results, as determined by the least variation between replicates and by microscopic examination of the wells. Accordingly, the last technique was used throughout the study. After washing, remaining fluorescence was determined as described above. Linear regression analysis of the standard curve was performed and this was used to determine the number of cells remaining in the experimental wells. If the neutrophils were not labeled, adhesion was determined by staining the wells with Stat Stain (VWR scientific) and counting adherent neutrophils in $4 \times 0.1 \mathrm{~mm}^{3}$ sections and multiplying the average by 320 (total surface area $32 \mathrm{~mm}^{3}$ ).

\section{Evaluation of superoxide generation}

Superoxide production by neutrophils was determined using a ferricytochrome $c$ reduction method (Ward, 1983). Briefly, $1 \times 10^{6}$ labeled or unlabeled neutrophils were combined with $80 \mu \mathrm{M}$ cytochrome $c$ in the presence of $2.5 \mu \mathrm{g} / \mathrm{ml} \mathrm{cy-}$ tochalasin B in HBSS with $0.02 \%$ BSA (with or without $75 \mathrm{U} / \mathrm{ml}$ superoxide dismutase) in a final volume of $1 \mathrm{ml}$. The cells were stimulated for 30 $\min$ at $37^{\circ} \mathrm{C}$ with $1 \times 10^{-6} \mathrm{M}$ phorbol 12 -myristate acetate (PMA). The cells were then pelleted and the supernatant recovered and its absorbance at $550 \mathrm{~nm}$ determined. Total $\mathrm{O}_{2}^{-}$present was calculated using an extinction coefficient of 18.5 $\mathrm{cm} / \mathrm{mM}$.

\section{Inhibition of $r T N F \alpha$-induced adhesion by anti-E- selectin}

Monolayers of HUVEC were prepared and then stimulated with $25 \mathrm{ng} / \mathrm{ml} \mathrm{rTNF} \alpha$ for $4 \mathrm{~h}$ at $37^{\circ} \mathrm{C}$. The monolayers were washed twice; 0,5 or $50 \mu \mathrm{g} / \mathrm{ml}$ of a murine monoclonal antibody to human E-selectin (CL3), which has been characterized elsewhere (Mulligan et al., 1991), was added and the plates incubated for $15 \mathrm{~min}$. The HUVEC were gently washed and $1 \times 10^{5}$ stained neutrophils were added. The remainder of the assay was completed as described above.

\section{Results}

Fluoresence of neutrophils is directly proportional to cell number

Fluorescence of serial dilutions of neutrophils yielded a linear intensity-concentration relationship over wide ranges of fluorochrome and cell concentration. However, at very low cell concentrations there was a loss of linearity. Therefore, it was necessary to ascertain the range of cell concentration that yielded a linear relationship with fluorescence and to delineate the sensitivity of the technique. Three different concentrations of BCECF-AM were used to label the neutrophils, $10 \mu \mathrm{M}, 1 \mu \mathrm{M}$ and $0.1 \mu \mathrm{M}$. At the lowest cell concentration utilized (195 cells/well) all three concentrations of fluorochrome employed for labeling yielded fluorescence that was statistically significantly above the fluorescence in media alone (Table I). The presence of auto-fluorescent contaminants in the media became problematical when higher sensitivities were utilized (data not 


\section{TABLE I}

\section{CONDITIONS FOR DETECTION OF NEUTROPHIL} FLUORESCENCE

Detection of labeled neutrophils was possible with as few as 195 cells at all loading concentrations of BCECF-AM. Higher concentrations of BCECF-AM enabled the use of lower sensitivity settings resulting in less interference by auto-fluorescent contaminants $(n=4)$.

\begin{tabular}{lllll}
\hline $\begin{array}{l}\text { Concentration } \\
\text { of BCECF-AM } \\
(\mu \mathrm{M})\end{array}$ & $\begin{array}{l}\text { Instrument } \\
\text { setting }\end{array}$ & $\begin{array}{l}\text { Cell } \\
\text { Number }\end{array}$ & $\begin{array}{l}\text { Fluores- } \\
\text { cence }\end{array}$ & $p$ values \\
\hline 10 & 2 & 391 & $32 \pm 0.9$ & $<0.001$ \\
& & 195 & $27 \pm 0.3$ & $<0.001$ \\
& & 0 & $21 \pm 0.1$ & \\
1 & 3 & 391 & $187 \pm 0.9$ & $<0.001$ \\
& & 195 & $179 \pm 0.7$ & $<0.001$ \\
& & 0 & $165 \pm 0.7$ & \\
0.1 & 4 & 391 & $881 \pm 6.7$ & 0.002 \\
& & 195 & $854 \pm 4.3$ & 0.010 \\
& & 0 & $827 \pm 4.1$ & \\
\hline
\end{tabular}

shown). Therefore, BCECF-AM concentrations that allow measurements to be conducted at sensitivity settings of 3 or less were utilized.

Serial two-fold dilutions of cells $\left(1 \times 10^{5}-3.125\right.$ $\times 10^{3}$ cells/well) maintained a linear relationship with fluorescence with a correlation coefficient of 0.995 (Fig. 1). The upper limit of cells tested, $1 \times 10^{5}$, was more than adequate for an adhesion assay conducted in a 96-well plate. If higher cell concentrations were needed confirmation of linearity in these ranges would be required. This range of cells, however, provides for cell concentration measurements over a range of at least two orders of magnitude. The standard error of the mean (SEM) between replicates was always $<3 \%$ of the total fluorescence value, usually $<1 \%$. The ability of cell lysis to reduce measurement variability was examined but did not significantly reduce the already very low SEM (data not shown).

\section{Functional features of BCECF-AM-labeled neu- trophils}

Since stimulation of neutrophils is associated with changes in the adhesive property of the cells it is important that the cells not be altered by the staining procedure itself. Neutrophils labeled with

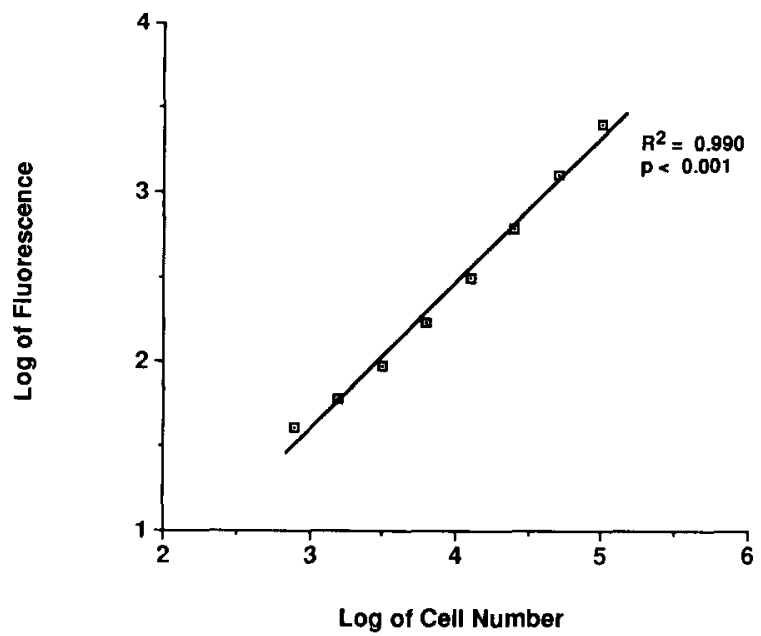

Fig. 1. The fluorochrome BCECF maintains a linear relationship with cell concentrations ranging from $5 \times 10^{5}$ to $3.125 \times$ $10^{3}$ neutrophils. Neutrophils were labeled with $1.0 \mu \mathrm{M}$ BCECF-AM and a standard curve of fluorescence intensity versus cell number was obtained. The log of the fluorescence was plotted against the $\log$ of the cell number and statistical analysis was performed using a 1-way ANOVA $(n=8)$.

three different concentrations of BCECF demonstrated similar adhesion to TNF $\alpha$-stimulated HUVEC monolayers as non-labeled neutrophils (Fig. 2). In addition, non-stimulated HUVEC monolay-

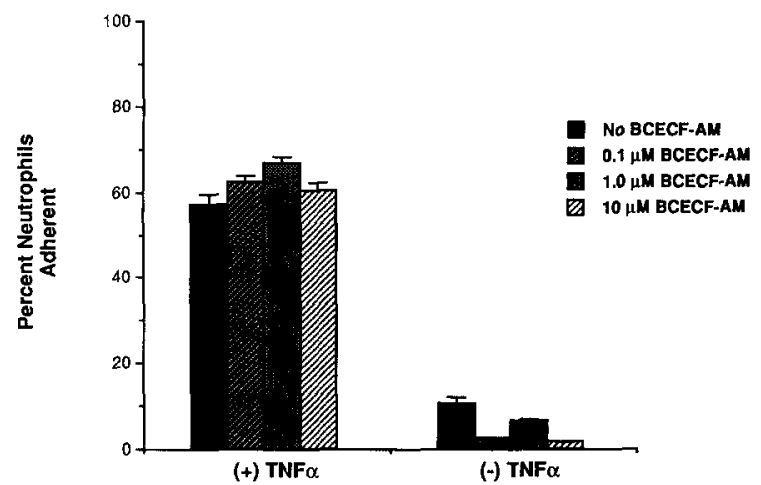

Fig. 2. BCECF-AM labeling of neutrophils did not alter their adherence to TNF $\alpha$-stimulated HUVEC monolayers. $57 \%$ of non-labeled neutrophils adhered to HUVEC monolayers that had been exposed to $2 \mathrm{ng}$ TNF $\alpha / \mathrm{ml}$ for $4 \mathrm{~h}$. Similar adhesion was present when the neutrophils were labeled with $0.1,1.0$ and $10 \mu \mathrm{M}$ BCECF-AM $(62 \%, 67 \%$ and $60 \%$ respectively, $p=$ NS). With unstimulated endothelial cells there was also minimal difference between non-labeled and labeled neutrophils $(10.6 \%$ versus $2.3 \%, 6.6 \%$ and $1.5 \%$ respectively, $p=\operatorname{NS})(n=4)$. 
ers demonstrated minimal adhesion with the labeled PMNs, regardless of the concentration of BCECF-AM used (Fig. 2). In order to assess if labeled neutrophils could still upregulate adhesive properties, we examined the ability of PMA to generate leukocyte-endothelial adhesion. Neutrophils were stained with $1 \mu \mathrm{M}$ of BCECF-AM, then stimulated with $10^{-8} \mathrm{M}$ PMA, and immediately allowed to interact with non-stimulated monolayers of HUVEC. Two standard curves were generated for this assay using either PMAstimulated or unstimulated neutrophils. The result was a rapid development of adhesion of up to $76 \%$ in the stimulated group (Fig. 3) (Varani et al., 1992).

In order to establish whether stimulation of the neutrophils had an effect upon fluorescence of BCECF, we generated standard curves using BCECF-labeled neutrophils that were stimulated with $10^{-8} \mathrm{M}$ PMA and compared them to nonstimulated BCECF-labeled neutrophils. The effect of TNF $\alpha$ stimulation of endothelial monolayers on the fluorescence of BCECF-labeled neutrophils was determined in a similar fashion. PMA stimulation, using the conditions indicated, resulted in a $23 \%$ reduction of fluorescence at all neutrophil concentrations. The stimulated HUVEC monolayers had no effect on the fluorescence of the BCECF-labeled neutrophils (Fig. 4).

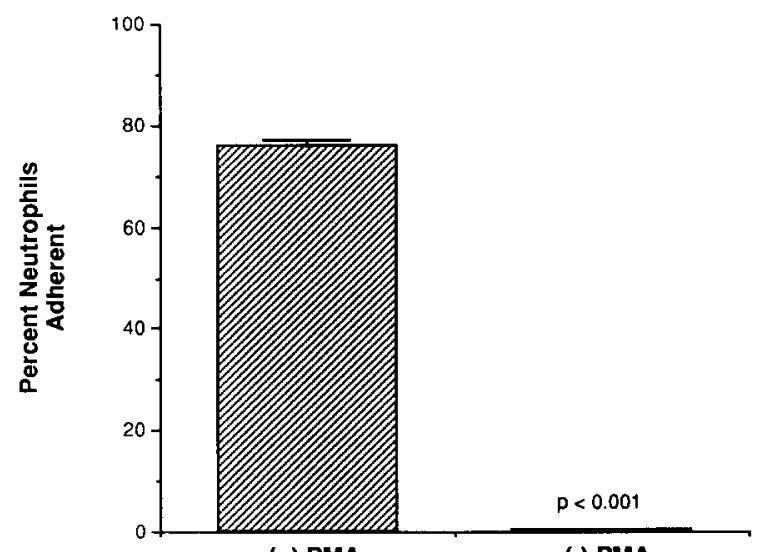

(+) PMA

(-) PMA

Fig. 3. PMA-dependent adhesion of BCECF-AM labeled neutrophils. $76 \%$ of neutrophils labeled with $1.0 \mu \mathrm{M}$ BCECF-AM and exposed to $10^{-8} \mathrm{M}$ PMA adhered to unstimulated $\mathrm{HU}$ VEC monolayers $(n=4)$.
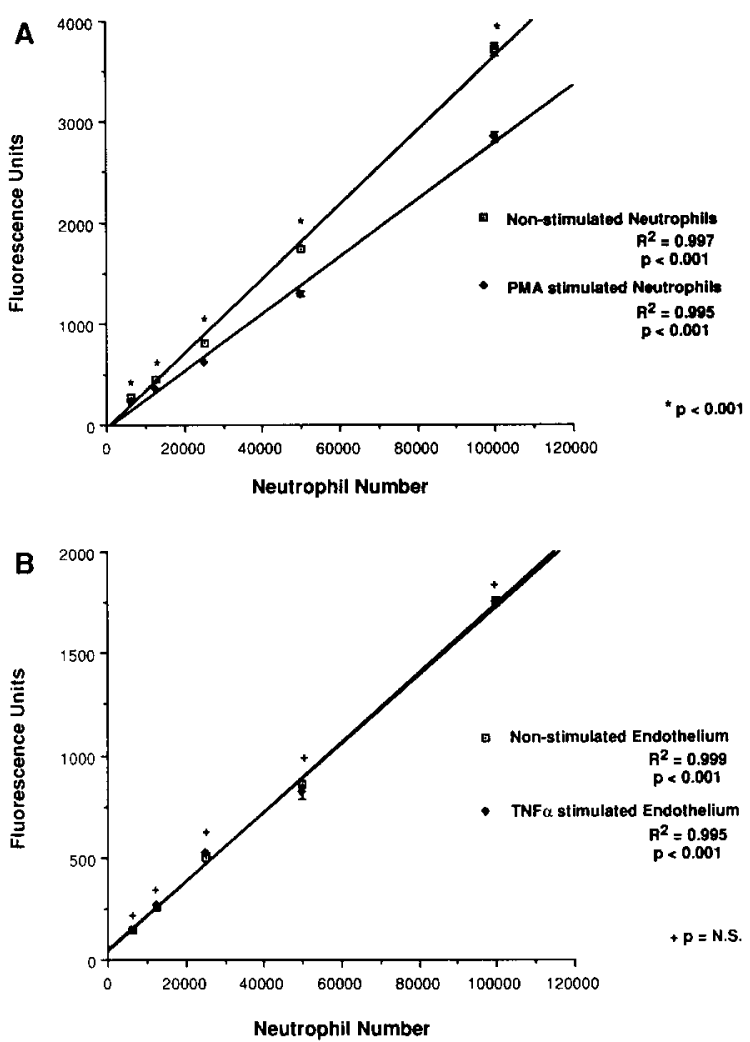

Fig. 4. Neutrophil activation caused a decrease in BCECF fluorescence. In $A$, labeled neutrophils were exposed to $10^{-8}$ M PMA for $30 \mathrm{~min}$ and their fluorescence compared to unstimulated labeled neutrophils. The stimulated neutrophils had $23 \pm 0.96 \%$ less fluorescence at all cell concentrations $(p<0.001)$. However, HUVEC monolayers $(B)$ exposed to 4 $\mathrm{h}$ of $2 \mathrm{ng} \mathrm{TNF} \alpha / \mathrm{ml}$ caused no statistical difference in the fluorescence of BCECF-labeled neutrophils versus unstimulated endothelium $(n=4)$.

To further demonstrate the effect of labeling on functional response of neutrophils, we measured the generation of $\mathrm{O}_{2}^{-}$by PMA-stimulated cells. Labeled neutrophils produced similar amounts of $\mathrm{O}_{2}^{-}$compared to non-stained cells with or without PMA (20 $\mathrm{ng} / \mathrm{ml})$ stimulation (Fig. 5).

\section{Utilization of assay for cell adhesion}

In order to demonstrate the utility of BCECFAM labeling method for the rapid detection of adhesive interactions of neutrophils with endothelial monolayers, we studied the effects of TNF $\alpha$ stimulation of HUVEC monolayers. La- 


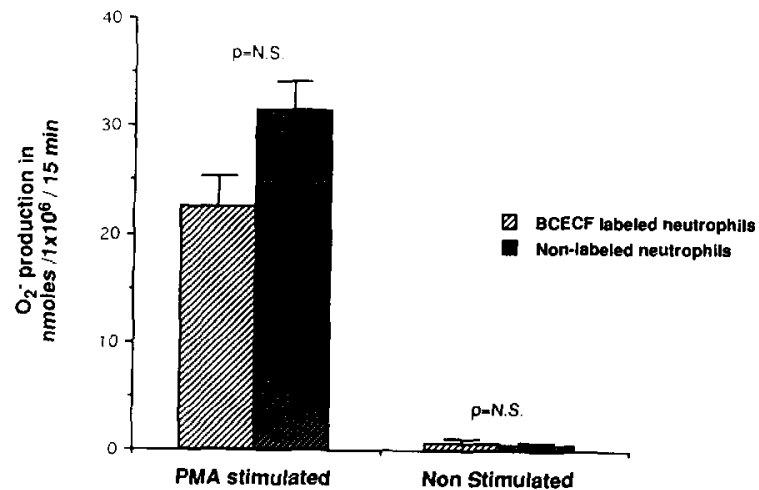

Fig. 5. BCECF-AM labeling does not cause a significant difference in PMA-dependent neutrophil $\mathrm{O}_{2}^{-}$production. $1 \times$ 106 labeled neutrophils produced $22 \pm 2.9$ nmoles $/ 30 \mathrm{~min} \mathrm{O}_{2}^{-}$ and unlabeled neutrophils produced $31 \pm 2.7$ nmoles $/ 30 \mathrm{~min}$ $\mathrm{O}_{2}^{-}$exposure to $10^{-8}$ M PMA ( $p=\mathrm{NS}$ ). Non-stimulated labeled and unlabeled neutrophils produced $0.5 \pm 0.6$ and $0.4 \pm 0.4$ nmoles $/ 30 \mathrm{~min} \mathrm{O}_{2}^{-}(p=\mathrm{NS})(n=4)$.

beled human neutrophils were used to generate a dose-response curve and a time course for the effects of endothelial preexposure to TNF $\alpha$. Both sets of data were generated on the same microtiter plate and completed within $5 \mathrm{~h}$, including isolation of the neutrophils. The results are consistent and demonstrate that doses of TNF $\alpha$ as low as $1 \mathrm{ng} / \mathrm{ml}$ will produce maximal upregulation of adhesive interactions with neutrophils. Increased adhesive interactions between neutrophils and HUVEC occurred when $0.1 \mathrm{ng}$

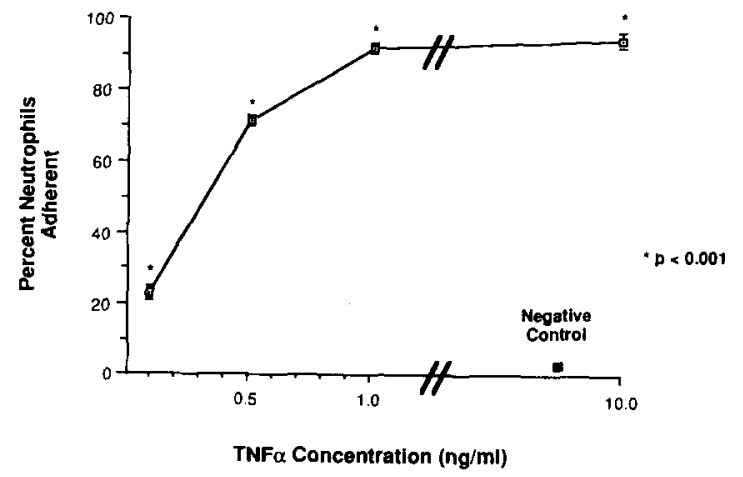

Fig. 6. Adhesive interaction between BCECF-AM-labeled neutrophils and HUVEC monolayers exposed to increasing doses of TNF $\alpha$ for $4 \mathrm{~h}$. The minimal concentration of TNF $\alpha$ which resulted in increased adhesive interactions was $0.1 \mathrm{ng}$ TNF $\alpha / \mathrm{ml}$. Adhesion was maximal at concentrations equal to or greater than $1 \mathrm{ng} \mathrm{TNF} \alpha / \mathrm{ml}(n=6)$.

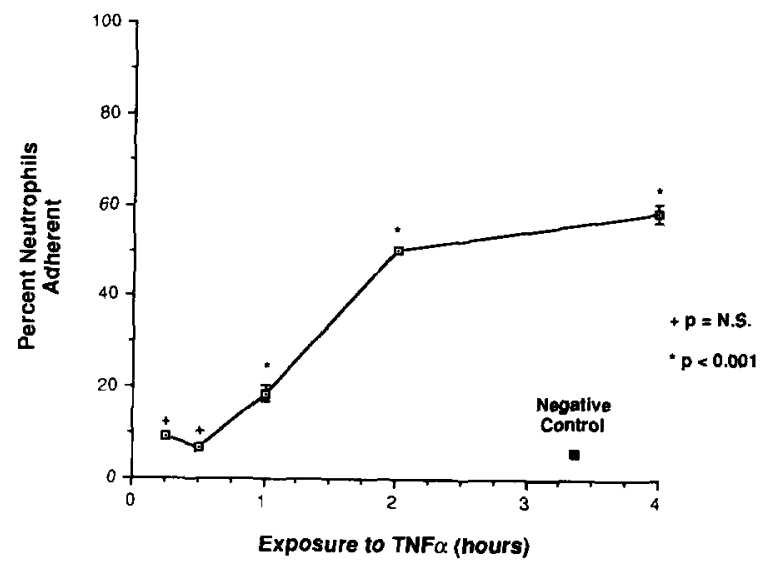

Fig. 7. Adhesive interaction between BCECF-AM-labeled neutrophils and HUVEC monolayers, time course of TNF $\alpha$ effects. Minimal adhesion was apparent after $1 \mathrm{~h}$ exposure to $2 \mathrm{ng} T \mathrm{TF} \alpha / \mathrm{ml}$. Maximal adhesive interactions were achieved after $2 \mathrm{~h}$ of incubation with TNF $\alpha(n=6)$.

$\mathrm{TNF} \alpha / \mathrm{ml}$ was used for pretreatment of the HUVEC. The adhesive interactions increased with rising doses of $\mathrm{TNF} \alpha$, with a plateau being achieved at $1.0 \mathrm{ng}$ TNF $\alpha / \mathrm{ml}$ (Fig. 6) (Gamble et

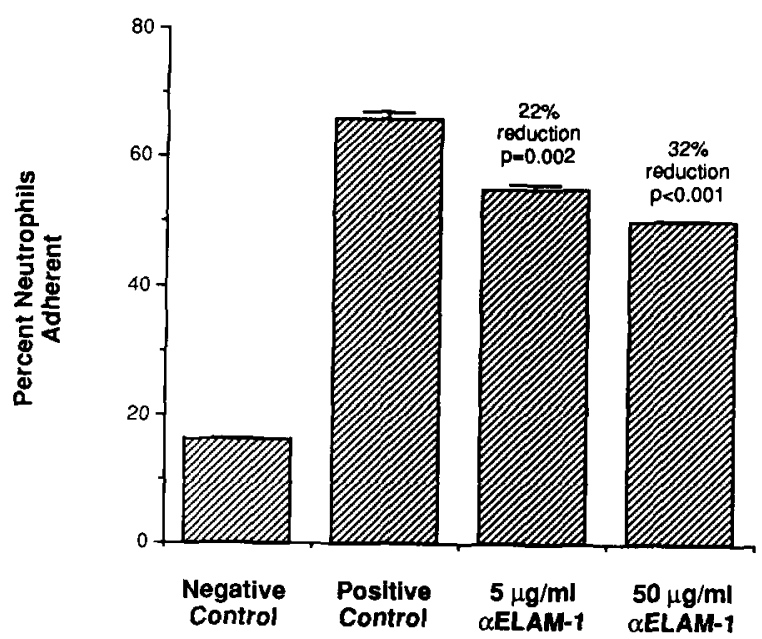

Fig. 8. Inhibition of adhesion between BCECF-AM-labeled neutrophils and TNF $\alpha$-stimulated HUVEC monolayers. A murine $\mathrm{IgG}_{1}$ antibody directed against human ELAM-1 (CL3) was added to the HUVEC monolayers during the last $15 \mathrm{~min}$ of their incubation with TNF $\alpha$. After washing the monolayers, labeled neutrophils and adherence determined as described in the materials and methods section. The positive and negative controls were $66 \pm 1.0 \%$ and $16 \pm 0.4 \%$. Using 5 and $50 \mu \mathrm{g}$ $\alpha$-ELAM- $1 / \mathrm{ml}$, inhibition of $22 \%(p=0.002)$ and $32 \%(p<$ $0.001)$ of adhesion was obtained when compared to the negative control $(n=4)$. 
al., 1985; Pohlman et al., 1986; McFaul and Bowman, 1990).

When a time course for the effects of TNF $\alpha$ ( 2 $\mathrm{ng} \mathrm{TNF} \alpha / \mathrm{ml})$ on adhesive interactions of neutrophils with endothelial monolayers was determined, exposure of the endothelial monolayers required at least $1 \mathrm{~h}$ in order for minimal adhesive interactions to be detected (Fig. 7). From $2 \mathrm{~h}$ and later, the adhesive interactions appeared to reach a plateau (Gamble et al., 1985; Pohlman et al., 1986; McFaul and Bowman, 1990).

The method described in this report can also be utilized to screen the effectiveness of antibodies directed against adhesion molecules. Anti-Eselectin (CL3) was employed as outlined in the materials and methods section. The antibody blocked adhesion in a concentration-dependent fashion with a $32 \%$ reduction at $50 \mu \mathrm{g} / \mathrm{ml}$ and $22 \%$ reduction at $5 \mu \mathrm{g} / \mathrm{ml}$ (Fig. 8), these findings being quatitatively similar to those employing a different technology (Mulligan et al., 1991). The reproducibility of the assay is demonstrated by the small SEM.

\section{Discussion}

The recent characterization of the molecules responsible for endothelial-leukocyte adhesive interactions has necessitated a detailed evaluation of these events. In vitro assays measuring the effects of cytokines and the contribution of specific adhesion molecules require the use of a large number of analyses. We describe here a rapid, safe, inexpensive and readily reproducible method of assessing adhesion. The assay allows for ready labeling of neutrophils. The resulting fluorescence follows a linear relationship over a wide range of cells employed. The labeling causes no measurable alterations in physiological responses to PMA as quantified by increased adhesion to endothelial monolayers or by $\mathrm{O}_{2}^{-}$production. Finally, the results employing this new analytical method agree with data obtained through the use of other published methods (Gamble et al., 1985; Pohlman et al., 1986; McFaul and Bowman, 1990; Mulligan et al., 1991).

Labeling cells to allow for quantitative assessment of functional characteristics is a common requirement of a variety of in vitro assays. The fluorescent compound BCECF can be used to rapidly and safely accomplish this goal. However, BCECF does vary its fluorescence with changes in $\mathrm{pH}$ and stimulation of labeled neutrophils with PMA resulted in altered fluorescence. Therefore, any stimulation of the neutrophils would require that a standard curve of similarly stimulated BCECF-labeled neutrophils be performed, as was done for Fig. 3. The advantage of this fluorochrome compared to common fluorescein derivatives is that it has one of the slowest rates of spontaneous release (Kolber et al., 1988). The loading of the cells occurs with the acetoxymethyl derivative of BCECF, which is permeable to the cell membrane. Once internalized, the ester linkage is cleaved by intracellular esterases, leaving the negatively charged, fluorescent BCECF. This negative charge, greater than on most other dyes, is likely responsible for the prolonged retention. Thus the BCECF is similar to ${ }^{51} \mathrm{Cr}$ as both are released in non-reusable forms.

Although other techniques of quantitating cell number are well established, fluorochromes offer certain advantages. The labeling is done under physiological conditions and is applicable to many cell types. Monocytes were also labeled and used in a similar adhesion assay as pilot experiments with very reproducible results (data not shown). The dye has not been found to alter cell function in a variety of systems including cytotoxicity and chemotaxis. Fluorescence microscopy allows for direct visual evaluation of results. The availability of automated plate readers greatly decreases the experimental time and errors introduced by multiple manipulations of samples. The lack of radioactive isotopes avoids all of their attendant problems. In addition, the fluorochromes have a much lengthier shelf-life than radio-isotopes such as ${ }^{51} \mathrm{Cr}$. Finally, the availability of fluorochromes with differing emission characteristics will allow multiple cell populations to be studied simultaneously, thus evaluating their effects upon each other in the same assay.

\section{Acknowledgement}

Supported by NIH grants HL31963 and HL07517. 


\section{References}

Barker, J.N.W.N., Jones, M.L., Swenson, C., Mitra, R.S., Fantone, J.C., Ward, P.A., Johnson, K., Dixit, V.M., Warren, J.S. and Nickoloff, B.J. (1991) Interleukin-8 (IL-8) production by human epidermal keritinocytes in response to tumor necrosis factor (TNF). Am. J. Path. 139, 869.

Beesley, J.E., Pearson, J.D., Carleton, J.S., Hutchings, A. and Gordon, J.L. (1978) Interaction of leukocytes with vascular cells in culture. J. Cell Sci. 33, 85.

Cosimi, A.B., Conti, D., Delmonico, F.L., Preffer, F.I., Wee, S.L., Rothlein, R., Faanes, R. and Colvin, R.B. (1990) In vivo effects on monoclonal antibody to ICAM-1 (CD54) in nonhuman primates with renal allografts. J. Immunol. 144, 4604.

Curwen, K.D., Kim, H.Y., Vazquez, M., Handin, R.I. and Grimbone, M.A. Jr. (1982) Platelet adhesion to cultured vascular endothelial cells. A quantitative monolayer adhesion assay. J. Lab. Clin. Med. 100, 425.

Flavin, T., Ivens, K., Rothlein, R., Faanes, R., Clayberger, C., Billingham, M. and Starnes, V.A. (1991) Monoclonal antibodies against intercellular adhesion molecule 1 prolong cardiac aliograft survival in cynomolgus monkeys. Transplant. Proc. 23, 533.

Gamble, J.R. and Vadas, M.A. (1988) A new assay for the measurement of the attachment of neutrophils and other cell types to endothelial cells. J. Immunol. Methods 109, 175.

Gamble, J.R., Harlan, J.M., Klebanoff, S.J. and Vadas, M.A (1985) Stimulation of the adherence of neutrophils to umbilical vein endothelium by recombinant tumor necrosis factor. Proc. Natl. Acad. Sci. USA 82, 8667.

Haskard, D.O., Strobel, S., Thornhill, M., Pitzalis, C. and Levinsky, R.J. (1989) Mechanisms of lymphocyte adhesion to endothelial cells: studies using a LFA-1-deficient cell line. Immunology $66,111$.

Jaffe, E.A. (1984) Culture and identification of large vessel endothelial cells. In: E.A. Jaffe (Ed.), Biology of Endothelial Cells. Martinus Nijhoff, The Hague, p. 1.

Kolber, M.A., Quinones, R.R., Gress, R.E. and Henkart, P.A. (1988) Measurement of cytotoxicity by target cell release and retention of the fluorescent dye bis-carboxyethlycarboxyfluorescein (BCECF). J. Immunol. Methods 108, 255.

Lindbom, L., Lundberg, C., Prieto, J., Raud, J., Nortamo, P., Gahmberg, C.G. and Patarroyo, M. (1990) Rabbit leukocyte adhesion molecules CD11/CD18 and their participation in acute and delayed inflammatory responses and leukocyte distribution in vivo. Clin. Immunol. Immunopath. 57, 105.

McFaul, S.J. and Bowman, P.D. (1990) Quantitation of polymorphonuclear leukocyte adherence to endotheIial cells by electronic particle size discrimination. J. Immunol. Methods 130, 171.

Mulligan, M.S., Varani, J., Dame, M.K., Lane, C.L., Smith, C.W., Anderson, D.C. and Ward, P.A. (1991) Role of endothelial-leukocyte adhesion molecule 1 (ELAM-1) in neutrophil-mediated lung injury in rats. J. Clin. Invest. 88, 1396.

Pearce-Pratt, R. and Phillips, D.M. (1992) Studies of adhesion of lymphocytes to epithelia: implication of sexual transmission of HIV. Biol. Reprod. submitted.

Pohlman, T.H., Stanness, K.A., Beatty, P.G., Ochs, H.D. and Harlan, J.M. (1986) An endothelial cell surface factor(s) induced in vitro by lipopolysaccharide, interleukin 1 , and tumor necrosis factor $\alpha$ increases neutrophil adherence by a CDw18-dependent mechanism. J. Immunol. 136, 4548.

Roszkowski, W., Bleuth, J., Ko, H.L., Uhlenbruck, G. and Pulverer, G. (1989) Blocking of lectin-like adhesion molecules on pulmonary cells inhibits lung sarcoma L-1 colonization in BALB/c-mice. Experientia 45, 584.

Varani, J., Dame, K.D., Gibbs, D.F., Taylor, C.G., Weinberg, J.M., Shayevitz, J. and Ward, P.A. (1992) Human umbilical vein endothelial cell killing by activated neutrophils: loss of sensitivity to injury is accompanied by decreased iron content during in vitro culture and is restored with exogenous iron. Submitted.

Ward, P.A., Duque, R.E., Sulavik, M.C. and Johnson, K.J. (1983) In vitro and in vivo stimulation of rat neutrophils and alveolar macrophages by immune complexes. Production of $\mathrm{O}_{2}^{-}$and $\mathrm{H}_{2} \mathrm{O}_{2}$. Am. J. Path. 110, 297. 